\title{
NOTES ON THE BAUMÉ SCALES IN USE IN THE UNITED STATES.*
}

By H. W. Bearce.

[ABSTRACT.]

THE paper gives the origin, history, and present status of the Baumé scales in use in the United States, with special reference to the scale used in the petroleum oil industry. It is intended to correct certain misinformation in regard to the basis and time of adoption of the American Standard Baumé Scale for liquids lighter than water. It is of interest in connection with the Petroleum Oil Tables recently issued by the Bureau of Standards (Circular No. 57).

\section{STANDARDIZATION OF AUTOMOBILE TIRE FABRIC TESTING. $\dagger$}

\author{
By W. S. Lewis and C. J. Cleary.
}

[ABSTRACT.]

THIS work was undertaken with the view to standardizing the more important methods of tests made upon $17 / 4$-ounce cotton tire fabric. There was found little or no uniformity in the methods of testing employed by the various mills, and this had given rise to confusion in the interpretation of results of tests. In order to assist in the betterment of this condition, the Bureau, in coöperation with fabric and tire manufacturers, undertook to determine the methods of test most suitable for these fabrics.

The chief causes of variation in test results are due to different tensile strength testing machines, dimensions of test specimens, moisture content of specimen at time of test, method of sampling, and lack of uniformity in the material. Several long series of comparative tests were made to determine which of the several proposed methods for ascertaining each particular physical property of the fabric would give the most consistent and reliable results.

* Scientific Paper No. 276 .

$\dagger$ Technological Paper No. 68. 